\title{
Integrating the Extended Theory of Planned Behavior With the Stages of Change to Predict Exercise Among Chinese People With Type 2 Diabetes
}

\section{OPEN ACCESS}

Edited by:

Razak M. Gyasi,

African Population and Health Research Center (APHRC), Kenya

Reviewed by:

Andrew Soundy,

University of Birmingham,

United Kingdom

Pengwei HU

Merck, Germany

${ }^{*}$ Correspondence:

Xinying Sun

xysun@bjmu.edu.cn

XingLin Feng

fx।@bjmu.edu.cn

Specialty section: This article was submitted to Aging and Public Health, a section of the journal Frontiers in Public Health

Received: 08 September 2021 Accepted: 25 October 2021 Published: 19 November 2021

Citation:

Gao M, Chen P, Sun X, Feng X and

Fisher $E B$ (2021) Integrating the Extended Theory of Planned Behavior With the Stages of Change to Predict Exercise Among Chinese People With

Type 2 Diabetes.

Front. Public Health 9:772564. doi: 10.3389/fpubh.2021.772564

\begin{abstract}
Min Gao ${ }^{1,2}$, Ping Chen ${ }^{1}$, Xinying Sun ${ }^{1 *}$, XingLin Feng ${ }^{3 *}$ and Edwin B. Fisher ${ }^{4}$
${ }^{1}$ School of Public Health, Peking University Health Science Center, Beijing, China, ${ }^{2}$ Nuffield Department of Primary Care Health Sciences, University of Oxford, Oxford, United Kingdom, ${ }^{3}$ Department of Health Policy and Management, School of Public Health, Peking University, Beijing, China, ${ }^{4}$ Department of Health Behavior, Gillings School of Global Public Health University, Chapel Hill, NC, United States
\end{abstract}

Background: There have been very limited prospective studies examining social-cognitive models within stages of behavior change in the exercise domain.

Purpose: We examined the utility of the theory of planned behavior (TPB), incorporating self-identity and descriptive norm constructs, to predict exercise behavior across the stages of change, in individuals with type 2 diabetes.

Methods: Data were obtained from a longitudinal study. Multi-group structural equation modeling was used to estimate the association between extended TPB constructs and exercise within different stages groups.

Results: 647 individuals completed a self-report questionnaire at baseline and at 3 months follow-up. The extended TPB model explained $8-15 \%$ variance of exercise behavior and $42-81 \%$ variance of exercise intention within three stages groups in the cross-sectional design. The extended TPB model explained $4 \%-13 \%$ variance of exercise behavior and $42-66 \%$ variance of exercise intention in the longitudinal design. Intention was significantly related to exercise behavior in the pre-action and action stages. Self-identity, perceived behavioral control and descriptive norms were stronger predictors of intention in different stages.

Conclusion: Discontinuity patterns in the extended theory of planned behavior for the different stages groups were found. Intention was a significant predictor of exercise in the pre-action and action stages at 3 months.

Keywords: exercise, physical activity, type 2 diabetes, extended theory of planned behavior, stages of change, self-identity, descriptive norm constructs

\section{INTRODUCTION}

Over the past three decades, the prevalence of diabetes has increased in China from $<1 \%$ in 1980 to $12.8 \%$ in 2017 (1). Exercise is recommended for all individuals with diabetes as a part of the management of glycemic control (2-4). However, many studies have shown that the percentage of Chinese patients with type 2 diabetes who start exercising is lower $(5,6)$. It is crucial that the determinant factors of exercise activity among people with type 2 diabetes be explored and that effective interventions be promoted. 
Ajzen's theory of planned behavior (TPB) has been widely applied to and discussed for interventions involving exercise (711). The TPB includes four main constructs: attitude, subjective norm, perceived behavioral control (PBC), and intention. It is hypothesized that the intention is a function of attitude toward the behavior, subjective norm and PBC (12). The theory has been used extensively in the prediction of exercise in people with type 2 diabetes (13-15). One study in Australia found that in patients with type 2 diabetes, intention could explain $28 \%$ of the variance in exercise, and attitude, subjective norm, and $\mathrm{PBC}$ could explain $73 \%$ of the variance in intention (16). TPB was popular due to its ability to explain and predict and its operability of how to measure the variables (17).

Many previous studies have applied TPB to explain and predict a wide range of behaviors $(7,18-20)$. And it has been found that there were some limitations of TPB. Firstly, it is insufficient for TPB to explain a complicated psychological mechanism. So many studies modified TPB to add important factors to explain or predict specific behaviors (21-23). And Ajzen further suggested that the TPB was open to further expansion if additional predictors could be identified that explained more variance when included (24). Secondly, it was found that the past behavior contributed an extra $19 \%$ variance to the prediction of exercise controlling for other TPB variables (25). And it has been indicated that TPB had less power in longitudinal design comparing with cross-sectional design (7). Thirdly, TPB has been demonstrated different efficacy on different behavior types which means only one behavior would be focused on. A systematic review of 237 prospective studies showed that physical activity was better predicted among different behavior types (7). Finally, TPB focused on rational things but excluded the influence of unconsciousness and the role of emotion (12).

In order to make up for these limitations of TPB, we added two another factors self-identity and subjective norms to help explain and predict exercise. Self-identity can be conceptualized as the salient aspects of an individual's sense of self that are related to certain behaviors (26). For example, people who strongly view themselves as physically fit individuals are more likely to participate in physical activities. Increasingly, studies are finding that inclusion of self-identity explains more variance in behavioral intention, after accounting for traditional ТРВ constructs (27-29). A meta-analysis of 40 independent studies explored the role of self-identity in the TPB and found that the inclusion of self-identity could explain $6 \%$ additional variance in intentions (30).

Subjective norms can be described as the individual's perceptions of what important others think ought to be done (injunctive norms) (31). Ajzen and Fishbein suggested that the subjective norm construct should also include the individual's perceptions of what important others do (descriptive norms), in addition to injunctive norms. One meta-analysis found that the relationship between descriptive norm and behavioral intention was stronger in health-promoting behaviors, such as exercise (32). However, the implications for exercise interventions are limited, because the meta-analysis only included two studies on exercise behavior, and both studies included only college students.
It has been indicated that TPB was unsuitable for longitudinal study due in part to the fact that it would be influenced severely by past behavior. So in this study, the stages of change model was integrated with the extended TPB (30). The stages of change model could assess the current status of behavior. It is expected that TPB could show better predictive ability when people are separated according to different stages other than regarded as a whole.

The stages of change (30) model proposes that there are five stages of change: pre-contemplation, contemplation, preparation, action, and maintenance. People at different stages will think and behave in qualitatively different ways (33). A limited number of studies have explored the application of the TPB to the prediction of stage-specific patterns of physical activity. These studies have found that the magnitude of the effect size of social-cognitive variables on behavior was different in different stages of behavior $(34,35)$.

Therefore, this study aimed to (a) test the validity of an extended version of the TPB, which included self-identity and descriptive norm, for predicting exercise, and (b) examine the stage-specific effects of the extended TPB on exercise behavior using the stages of change model.

\section{MATERIALS AND METHODS Study Design and Setting}

This is a longitudinal study. The participants were recruited by cluster sampling from 22 community health centers in Beijing (in the Shunyi and Tongzhou districts) from July to November in 2018 (36).

Questionnaire survey was conducted at baseline and at 3-month follow-up through one-to-one interviews by welltrained investigators. Every investigator was trained before every investigation through standard lessons by the same trainer and investigators were asked to simulate the inquiry with each other.

At each health center, a team of physicians and nurses was responsible for the recruitment of participants, and collecting blood samples and biomarkers (including height, weight, waist circumference, and blood pressure). Welltrained investigators conducting face-to-face interviews for questionnaire investigation.

\section{Participants}

Inclusion criteria were as follows: aged between 18 and 70 years; hemoglobin Alc $\left(\mathrm{HbA}_{1 \mathrm{c}}\right) \geq 7.5 \%$ (as a measure of glucose control); permanent residence in Shunyi or Tongzhou district; without severe intellectual disability, Alzheimer's disease, or other mental disorders; not participating in other scientific studies; and agreeing to participate. Exclusion criteria included severe diabetes complications or other severe diseases.

There were 819 potential participants at baseline. According to the requirements for calculating sample size of structural equipment model (37), the degree of freedom of the structural equation model can be calculated as 204. When $\alpha=0.05, \beta=0.1$ and RMSEA reached 0.05 , the required sample size was 133 . So the participants were enough. Of those 819 potential participants, 665 people were followed after 3 months. Individuals who did 
not provide sufficient information on demographic and lifestyle factors were excluded from the study $(n=18)$. Data from the 647 individuals were included in the final analysis. This study was conducted in accordance with the Declaration of Helsinki. All participants provided prior written informed consent. Approval for the study was obtained from Medical Ethics Committee of Peking University (IRB00001052-17044).

\section{Measurement Covariates}

This data was obtained from a longitudinal study which divided the participants into two groups of intervention and control group. The difference between the groups lies in the doctorpatient relationship. The doctor-patient relationship at each community health station was categorized into two categories: directive support (the doctor assumes most of the responsibility for the management of the patient's condition and tells patients how they should do) and nondirective support (the doctor cooperates with patients and accepts their advice) (38). Moreover, stages of diet behavior (precontemplation, contemplation, preparation, action, and maintenance) and stages of medication behavior (precontemplation, contemplation, preparation, action, and maintenance) were also assessed and were considered into covariates.

Other variables were gender (women and men), age $(\leq 50$, $51-55,56-60,61-65$, and $\geq 66$ ), marital status (married and single), education level (primary school and below, middle school, high school, and university and above), and household monthly income per person $(<3,000,3,000-3,999,4,000-$ $4,999,5,000-9,999, \geq 10,000)$. Smoking status was classified into three categories: current smoker, past smoker, and nonsmoker. Drinking status was also classified into three categories: current drinker, past drinker, and nondrinker. Body mass index (BMI) was calculated by height and weight measurements. Diabetes duration was calculated as current year minus age at diagnosis. Hemoglobin A1c (\%) at baseline was treated as a continuous variable.

\section{Self-Reported Exercise}

Self-reported exercise was measured with the Chinese version of the International Physical Activity Questionnaire at baseline and 3 months. The questionnaire was used to collect data on the frequency of engagement in common high-, moderate-, and lowintensity exercises (39). Durations of these different intensities of exercise were set for at least $10 \mathrm{~min}$ per bout. The equation for the amount of exercise was as follows:

Total metabolic equivalents (METs) $=$ METs (activities of moderate intensity were defined as 4 METs; activities of vigorous intensity were defined as 8 METs) $\times$ days of exercise per week $\times$ duration for exercise per day.

\section{Stages of Change}

Stage of change was assessed with five-category measure in health behavior participation, which was a one-item questionnaire developed by Prochaska and Marcus (40). Participants were classified into one of five stages: (1) pre-contemplation (do not participate in exercise and do not intend to start), (2) contemplation (do not participate in exercise but are considering starting), (3) preparation (do not participate in exercise but plan to start soon); (4) action (are currently participating in exercise), and (5) maintenance (have participated in exercise for 6 months or more). The questionnaire was used to collect data on stages of exercise, diet, and medication behaviors.

\section{Extended TPB Questionnaire}

A questionnaire based on the variables of extended TPB was designed for this study. The questionnaire was designed to reflect Chinese culture and the current social situation. We designed several items for each dimension. Participants were allowed to choose the options of 5 degrees from "totally disagree" to "totally agree."

The dimension of intention reflected the intention to exercise such as "I have planned when to exercise regularly." The items of attitude focus on whether the attitude to exercise is positive, such as "Exercise is very effective for controlling blood sugar." Self-identity means whether the participants think they are fit to exercise, such as "I think I am good at exercising." Subjective norm reflects the opinion of someone else important, such as "People who are important to me think that I should exercise regularly." And descriptive norm was conceptualized as the perception of what important others do, such as "Many friends with T2D are exercising regularly." $\mathrm{PBC}$ were conceptualized as questions like "I've figured out how to solve the problems I might encounter during exercise." The specific items are presented in Appendix, Table A.

Reliability and validity for the measurement of self-identity, subjective norm, descriptive norm, intention, and perceived behavioral control are presented in Appendix, Table A. Cronbach's alpha values for each factor were as follows: intention (0.960), attitude (0.747), self-identity (0.750), subjective norm (0.63), descriptive norm (0.621), and PBC (0.653).

\section{Data Analysis}

Due to the limited number of participants in the precontemplation, contemplation, and preparation stages at baseline, we grouped these individuals into a pre-action group. Descriptive statistics (frequencies, proportions, means, and standard deviations) within three stages were examined. The chi-square test and one-way analysis of variance were used to estimate the differences across three stages. Variables were tested for skewness and kurtosis, and the differences were measured with the Kruskal-Wallis test if not normally distributed. Factor analysis was used to measure construct validity, and Cronbach's alpha was used to measure internal consistency. The correlations between subscales in the cross-sectional and longitudinal design were estimated. Structural equation modeling was conducted in the total population to predict exercise intention and exercise. The baseline model (baseline extended TPB constructs and baseline exercise) and the full model (baseline extended TPB constructs and exercise behavior at follow-up) were tested among participants in baseline stage groups. A maximum likelihood estimator was used to construct and fit the two models. Data were analyzed with STATA 14.0 (StataCorp LLC, College Station, 
TX, USA), and structural equation models were constructed using Mplus 7.0 (Muthén \& Muthén, Los Angeles, CA, USA).

\section{RESULTS}

\section{Stage-Based Demographic Characteristics and Exercise}

Stage-based differences in demographic variables are shown in Table 1. Compared at baseline and at 3 months, differences in exercise volume were significant across stages $(P<0.001)$. At baseline, participants in the maintenance (mean $=17.80$ [SD $=43.42]$ ) and action stages (mean $=12.36[\mathrm{SD}=28.71]$ ) had significantly higher exercise volume than participants in the pre-action stage $($ mean $=0.46[\mathrm{SD}=1.71])$.

At baseline, significant stage-based differences were observed for dietary behavior $(P<0.001)$, smoking status $(P<0.05)$, BMI $(P<0.01)$, and $\mathrm{HbA}_{1 \mathrm{c}}$ at baseline $(P<0.01)$. Across all exercise behavior stages, $48.68 \%$ of participants had not started diet control, whereas $90.41 \%$ had already taken medication. Most people did not smoke (60.59\%) or dink (62.44\%). Participants in the pre-action stage had higher BMIs (mean $=27.78$ [SD = $4.71]$ ), longer diabetes durations (mean $=5.10[\mathrm{SD}=3.80]$ ), and higher $\mathrm{HbA}_{1 \mathrm{c}}$ levels (mean $=7.45[\mathrm{SD}=1.49]$ ).

\section{Scores of Extended TPB Constructs}

The means and standard deviations for each construct across the three stages of change are presented in Table 2. The scores of all constructs in the advanced stages of exercise were significantly higher than those in the less advanced stages. Scores of all constructs in the pre-action stage were the lowest compared with those in the other stages.

\section{Cross-Sectional Structural Equation Modeling to Explain Exercise}

Multi-group structural equation modeling was used to estimate the internal correlations of exercise and components of the extended TPB in the three stages at baseline and at 3 months follow-up. Pearson correlations between the TPB measures between baseline and 3 months were estimated (Appendix, Table B). Goodness-of-fit indexes of multilevel structural equation models at baseline and at 3 months are presented, along with other detailed information, in Appendix, Table C. As is shown in Table 3, the baseline model accounted for 8,15 , and $11 \%$ of the variance of behavior in the pre-action, action, and maintenance stages. Explained variance in intention were 81,42 , and $49 \%$ in the pre-action, action, and maintenance stages. Intention was significantly related to exercise in the action $(\beta=0.20, P<0.05)$ and maintenance $(\beta=0.15, P$ $<0.001)$ stages. Self-identity $(\beta=0.56, P<0.001$ in the action stage, $\beta=0.34, P<0.001$ in the maintenance stage), $\mathrm{PBC}(\beta=$ $0.54, P<0.01$ in the pre-action stage, $\beta=0.40, P<0.001$ in the maintenance stage), and descriptive norm $(\beta=0.15, P<0.05$ in the maintenance stage) were stronger predictors of intention.

\section{Structural Equation Modeling to Predict Exercise at Follow-Up}

The full model explained 13,12, and $4 \%$ of the variance of behavior, 66 and $42 \%$, and $53 \%$ of the variance of intention across stages at 3 months. Baseline intention was significantly related to exercise in the pre-action $(\beta=0.33, P<0.05)$ and action stages $(\beta=0.13, P<0.05)$. No association between baseline PBC and exercise across the three stages was observed $(P>$ $0.05)$. Self-identity was associated with intention in the action $(\beta=0.56, P<0.001)$ and maintenance stages $(\beta=0.37, P$ $<0.001)$. PBC could predict intention in the pre-action $(\beta=$ $0.61, P<0.01)$ and maintenance stages $(\beta=0.42, P<0.001)$. Descriptive norm could predict intention in the maintenance stage $(\beta=0.14, P<0.05)$

\section{DISCUSSION AND CONCLUSION}

\section{Discussion}

\section{Main Findings}

This study provided evidence of the applicability of an extended TPB that adds self-identity and descriptive norm in the longitudinal design about exercise for patients with diabetes. Most importantly, a discontinuity pattern was observed across stages of exercise within the extended constructs of the TPB. Intention was a strong predictor of exercise. Self-identity, PBC, and descriptive norm were strong predictors of intention in different stages.

\section{Extended TPB Could Predict Exercise in Longitudinal Studies}

The explained variance for exercise at 3 months did not decline comparing with that at baseline, which provides evidence of the long-term utility of the extended TPB model integrating stages of change model. TPB showed better efficacy to predict exercise among different behavior types, and a meta-analysis found that TPB could explain $23.9 \%$ variance (7). It seemed that the degree of interpretation in this meta-analysis was higher than that in this study, but the type of study should be taken into consideration. Those studies included in meta-analysis were cross-sectional design. Our results were comparable to many longitudinal studies on the associations between TPB and exercise $(41,42)$. Plotnikoff demonstrated $8 \%$ variance explained by TPB on exercise behavior. As is shown in our results, the degree of explanation for different stages is different. And $8 \%$ is between maximum and minimum, which reminded us that the past behavior had influence on the actual behavior. A cohort of 1,427 adults showed that baseline TPB constructs could explain $13 \%$ of the variance in exercise behavior over a 15 -year period (43). The TPB in the cohort study also integrated other variables into TPB, such as moral norm.

\section{Intention Played Different Roles in Different Stages of Change}

The results of our study suggest that intention is essential in the prediction of exercise behavior, which is consistent with many studies $(7,44)$. In the cross-sectional analysis, intention was found to be significantly associated with behavior in the 
TABLE 1 | Change of exercise amount and baseline demographic characteristics across the stages of change.

\begin{tabular}{|c|c|c|c|c|c|}
\hline & Total & Pre-action & Action & Maintain & $X^{2} / F$ \\
\hline Baseline & $13.07(34.63)$ & $0.46(1.71)$ & $12.36(28.71)$ & $17.80(41.01)$ & $12.70^{\star \star \star}$ \\
\hline Gender (\%) & & & & & 2.89 \\
\hline Female & 51.62 & 51.88 & 57.89 & 49.34 & \\
\hline male & 48.38 & 48.12 & 42.11 & 50.66 & \\
\hline$\leq 50$ & 11.13 & 15.79 & 12.03 & 9.19 & \\
\hline $51-55$ & 15.15 & 17.29 & 11.28 & 15.75 & \\
\hline $56-60$ & 21.02 & 24.81 & 20.30 & 19.95 & \\
\hline $61-65$ & 28.90 & 27.07 & 32.33 & 28.35 & \\
\hline$\geq 66$ & 23.80 & 15.04 & 24.06 & 26.77 & \\
\hline Education level (\%) & & & & & 2.59 \\
\hline University and above & 17.16 & 17.29 & 15.04 & 17.85 & \\
\hline Marital status (\%) & & & & & 0.80 \\
\hline Single & 6.65 & 8.27 & 6.77 & 6.04 & \\
\hline Married & 93.35 & 91.73 & 93.23 & 93.96 & \\
\hline Household monthly income per person(\%) & & & & & 4.31 \\
\hline$<3,000$ & 29.83 & 29.32 & 33.83 & 28.61 & \\
\hline $3,000-3,999$ & 29.83 & 30.08 & 28.57 & 30.18 & \\
\hline 4,000-4,999 & 14.22 & 13.53 & 17.29 & 13.39 & \\
\hline$\geq 5,000$ & 26.12 & 27.07 & 20.30 & 27.82 & \\
\hline Stage of diet behavior (\%) & & & & & $65.00^{\star \star \star}$ \\
\hline Precontemplation & 35.24 & 38.35 & 27.07 & 37.01 & \\
\hline Preparation & 0.31 & 0.00 & 0.75 & 0.26 & \\
\hline Action & 3.55 & 3.76 & 7.52 & 2.10 & \\
\hline Maintenance & 86.86 & 90.23 & 84.21 & 86.61 & \\
\hline Smoke situation (\%) & & & & & $11.80^{*}$ \\
\hline Current smoker & 23.96 & 32.33 & 17.29 & 23.36 & \\
\hline Past smoker & 15.46 & 9.02 & 16.54 & 17.32 & \\
\hline Nonsmoker & 60.59 & 58.65 & 66.17 & 59.32 & \\
\hline Drink situation (\%) & & & & & 3.72 \\
\hline Current drinker & 29.68 & 23.31 & 30.08 & 31.76 & \\
\hline Past drinker & 7.88 & 9.77 & 7.52 & 7.35 & \\
\hline Nondrinker & 62.44 & 66.92 & 62.41 & 60.89 & \\
\hline BMI, Mean (SD) & $26.70(4.07)$ & $27.78(4.71)$ & $26.35(3.11)$ & $26.44(4.08)$ & $6.03^{\star \star}$ \\
\hline Diabetes duration, Mean(SD) & $4.83(3.53)$ & $5.10(3.80)$ & $4.57(2.66)$ & $4.83(3.69)$ & 0.74 \\
\hline $\mathrm{HbA}_{1 c}$ at baseline, Mean (SD) & $7.12(1.25)$ & $7.45(1.49)$ & $7.05(1.14)$ & $7.04(1.19)$ & $5.75^{\star \star}$ \\
\hline Doctors-patients relationship (\%) & & & & & 1.78 \\
\hline Directive support & 34.93 & 39.10 & 33.83 & 33.86 & \\
\hline Nondirective support & 33.69 & 33.08 & 32.33 & 34.38 & \\
\hline N & 647 & 133 & 133 & 381 & \\
\hline
\end{tabular}

Notes: $\mathbb{1}^{*} P<0.05 ;{ }^{* *} P<0.01 ;{ }^{* * *} P<0.001$.

(2) Total Metabolic Equivalents (METS), METS (moderate intensity activities were defined as 4 METs, vigorous intensity activities were defined as 8 METS) $\times$ days of exercise per week $\times$ duration for exercise per day. 
TABLE 2 | Means (standard deviations) for the extended TPB across the stages of change at baseline.

\begin{tabular}{lccccc}
\hline & Total & Pre-action & Action & Maintain & Chi \\
\hline Intention & $39.67(12.79)$ & $25.26(13.72)$ & $43.60(9.38)$ & $43.33(9.53)$ & 151.04 \\
Attitude & $22.04(3.08)$ & $21.30(3.52)$ & $22.24(3.03)$ & $22.23(2.90)$ & 7.22 \\
Self-identity & $18.11(4.31)$ & $15.37(4.83)$ & $18.51(4.43)$ & $18.92(3.64)$ & 60.001 \\
Subjective norm & $11.78(3.33)$ & $10.58(4.11)$ & $12.02(3.19)$ & $12.11(2.98)$ & 0.027 \\
Descriptive norm & $10.87(3.12)$ & $9.89(3.58)$ & $11.23(2.83)$ & $11.08(2.98)$ & $<0.001$ \\
PBC & $15.84(4.75)$ & $12.74(5.14)$ & $16.63(4.32)$ & $16.65(4.30)$ & 12.42 \\
\hline
\end{tabular}

All differences based on Kruskal-Wallis test. PBC, perceived behavior control.

TABLE 3 | Multiple regression analysis predicting behavioral intention and behavior across the stages.

\begin{tabular}{|c|c|c|c|c|c|c|}
\hline & \multicolumn{3}{|c|}{ Baseline model } & \multicolumn{3}{|c|}{ The full model } \\
\hline$R^{2}$ & 0.08 & 0.15 & 0.11 & 0.13 & 0.12 & 0.04 \\
\hline Intention & -0.02 & $0.20^{\star \star}$ & $0.15^{*}$ & $0.33^{*}$ & $0.13^{*}$ & 0.12 \\
\hline PBC & 0.23 & -0.03 & 0.09 & -0.12 & 0.05 & -0.04 \\
\hline$R^{2}$ & 0.81 & 0.42 & 0.49 & 0.66 & 0.42 & 0.53 \\
\hline Attitude & 0.18 & -0.11 & -0.02 & 0.08 & -0.16 & $-0.03)$ \\
\hline Self-identity & 0.03 & $0.56^{\star \star \star}$ & $0.34^{* \star \star}$ & 0.18 & $0.56^{\star \star \star}$ & $0.37^{\star \star \star}$ \\
\hline Subjective norm & 0.46 & 0.09 & 0.07 & 0.15 & 0.08 & 0.07 \\
\hline Descriptive norm & 0.14 & 0.13 & $0.15^{\star}$ & 0.16 & 0.12 & $0.14^{*}$ \\
\hline
\end{tabular}

(1) ${ }^{\star} P<0.05 ;{ }^{\star \star} P<0.01 ;{ }^{* \star \star} P<0.001$. $P B C$, perceived behavior control.

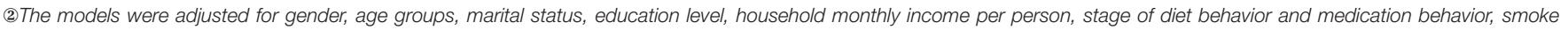
situation, drink situation, BMI, diabetes duration, $\mathrm{Hb} A_{1 \mathrm{C}}(\%)$ at baseline and doctors-patients relationship.

action and maintenance stages. However, in the longitudinal analysis, baseline intention was found to be a significant predictor of exercise over 3 months in the pre-action and action stages. Participants who have exercised for at least 6 months at baseline may have already developed an exercise routine, and their baseline intention to exercise could be underestimated. However, for patients who were in the pre-action stage at baseline, after 3 months, their intention has a relatively larger effect on exercise compared with patients in the action stage before. It may be that in people who had not started exercising before, the impact of intention on their behavior when they do start exercising is more significant compared with that of people who were exercising at baseline. This explanation is supported by the findings of one previous longitudinal study (45). PBC is another well-discussed predictor of behavior and intention that reflects one's ability to reduce the impact of other inhibiting factors, such as weather, environment, time, and effort (46). In our study, PBC can't predict exercise in all stages of exercise at 3 months. Many previous studies have found $\mathrm{PBC}$ to be more strongly associated with intention than with behavior $(47,48)$. It is possible that participants who have high levels of confidence are more likely to have good intentions to be physically active and that these intentions do not necessarily translate into action. However, in our study, PBC was strongly associated with intention in the pre-action and maintenance stages. PBC reflected one's ability to reduce the impact of other inhibiting factors.

\section{Variables of Extended TPB Contributed to Intention and Actual Behavior}

In line with many studies $(29,49,50)$, we found self-identity to be associated with intention in the action and maintenance stages at baseline and 3-month follow-up, suggesting that individuals who perceived themselves as physically active are more likely to have higher intentions to engage in exercise. There is evidence suggesting that the inclusion of self-identity measures in the TPB could account for additional variance in exercise intentions (26). Our study also found that the impact of self-identity on intention in patients in the action stage is greater than that in patients in the maintenance stage. As indicated in Table 2, people in the maintenance stage at baseline are more likely to identify themselves as physically fit. However, for patients in the action stage, increases in the scores of self-identity would exert greater influence on intention.

Our study found that descriptive norm was significantly associated with intention in the maintenance stage. Important others, such as friends, may have strong social influence on one's behavior (31), and the influence is more significant in the maintenance stage. For patients who continue exercising 
for more than 6 months, peer support and influence from important others may contribute to the maintenance of exercise participation (32).

Attitude and subjective norm were found to be insignificantly associated with intention across all stages in the cross-sectional and longitudinal analyses, which may be due to the characteristics of our sample. More than $90 \%$ of individuals agreed or strongly agreed that exercise offers health benefits, which may have reduced the magnitude of the association between attitude and intention. For subjective norm, 79\% of our sample had entered into the action and maintenance stages. They may have perceived less pressure from friends and peers because they had already been engaged in exercise. Many studies have found that subjective norm is a weak and non-significant predictor of intention (51, 52). Previous studies have suggested that subjective norm may be not associated with later stages of exercise because of a lack of instrumental value (53).

\section{Limitations}

Limitations in this study should be acknowledged. First, due to the limited number of participants, we had to combine participants in the pre-contemplation, contemplation, and preparation stages into one stage: the pre-action stage. Therefore, we were unable to analyze the differences among those three stages. Secondly, exercise activity was assessed with a selfreported questionnaire, which may have increased the risk of inaccurate recall. To increase the accuracy of the selfreported data, our investigators were trained to help people with diabetes understand the types and durations of exercise, and to encourage people with diabetes to recall recent exercise activity. Finally, there is a fact that behavior would be influenced by unconsciousness and emotions $(54,55)$. And it is obvious that perceived social support and environment would also affect behavior. But in this study, these factors were ignored. This point is also the limitation of Theory of Reasoned Action. In the future, researchers could contribute to this part.

\section{Conclusion}

This study has investigated discontinuity patterns across three stages of exercise within the extended TPB. Intention was found to strongly predict exercise in the pre-action and action stage. $\mathrm{PBC}$ and self-identity were significant predictors of intention in pre-action and action, respectively. Perceived behavioral control and descriptive norm was significantly associated with intention in the maintenance stage. These findings have underscored the qualitative differences between the stages and may further guide the research and the design of interventions integrating these approaches.

\section{Practice Implications}

Our study provides evidence toward the utility for practitioners and researchers to operationalize exercise interventions for

\section{REFERENCES}

1. Li Y, Teng D, Shi X, Qin G, Qin Y, Quan H, et al. Prevalence of diabetes recorded in mainland China using 2018 diagnostic criteria from the patients with diabetes, using an extended TPB that included self-identity and descriptive norm variables.

Our findings suggest that such interventions would need to promote the importance of exercise intention, with specific emphasis on the enhancement of positive self-identity and strong $\mathrm{PBC}$ beliefs in patients in the pre-action and action stages. For patients in the maintenance stage, encouraging self-control and self-recognition may lead to more physical activity. For example, assessing the stage of change before giving interventions. For patients in the pre-action and action stages, design special lectures for them to improve their self-identity and PBC beliefs. But for patients in the maintenance stage, contents of lectures need to focus on tips for maintaining self-discipline and persistence.

\section{DATA AVAILABILITY STATEMENT}

The raw data supporting the conclusions of this article will be made available by the authors, without undue reservation.

\section{ETHICS STATEMENT}

All participants provided prior written informed consent. Approval for the study was obtained from Medical Ethics Committee of Peking University (IRB00001052-17044).

\section{AUTHOR CONTRIBUTIONS}

MG, XYS, and XLF contributed to the conception and design of the work. MG and XYS contributed to the acquisition, analysis, or interpretation of data. EBF guided the investigation. MG and PC drafted the manuscript and are co-first authors. XYS and XLF critically revised the manuscript. All authors contributed to the article and approved the submitted version.

\section{FUNDING}

This work was funded by the National Natural Science Foundation of China (Grant Nos. 71673009 and 72174008).

\section{ACKNOWLEDGMENTS}

We appreciate the community health workers in Shunyi and Tongzhou District, who have contributed considerable energy in this study.

\section{SUPPLEMENTARY MATERIAL}

The Supplementary Material for this article can be found online at: https://www.frontiersin.org/articles/10.3389/fpubh. 2021.772564/full\#supplementary-material

American Diabetes Association: national cross sectional study. BMJ. (2020) 369:m997. doi: 10.1136/bmj.m997

2. Gillen J, Little J, Punthakee Z, Tarnopolsky M, Riddell M, Gibala M. Acute high-intensity interval exercise reduces the postprandial 
glucose response and prevalence of hyperglycaemia in patients with type 2 diabetes. Diabetes, Obesity and Metabolism. (2012) 14:575-7. doi: 10.1111/j.1463-1326.2012.01564.x

3. Avery L, Flynn D, Van Wersch A, Sniehotta FF, Trenell MI. Changing physical activity behavior in type 2 diabetes: a systematic review and meta-analysis of behavioral interventions. Diabetes Care. (2012) 35:26819. doi: $10.2337 / \mathrm{dc} 11-2452$

4. Sigal RJ, Kenny GP, Wasserman DH, Castaneda-Sceppa C. Physical activity/exercise and type 2 diabetes. Diabetes Care. (2004) 27:251839. doi: $10.2337 /$ diacare.27.10.2518

5. Wang R, Zhang P, Lv X, Jiang L, Gao C, Song Y, et al. Situation of diabetes and related disease surveillance in rural areas of Jilin Province, Northeast China. Int J Environ Res Public Health. (2016) 13:538. doi: 10.3390/ijerph13060538

6. Ye Chen QC, Wan L. Current status of physical exercise and its influencing factors in patients with type 2 diabetes. Hu Li Yan Jiu. (2010) 24:598-600.

7. Hagger MS, Chatzisarantis NL, Biddle SJ, A. meta-analytic review of the theories of reasoned action and planned behavior in physical activity: Predictive validity and the contribution of additional variables. J Sport and Exercise Psychology. (2002) 24:3-32. doi: 10.1123/jsep.24.1.3

8. Thompson EL, Vamos CA. Daley EM. Physical activity during pregnancy and the role of theory in promoting positive behavior change: A systematic review. J Sport Health Sci. (2017) 6:198-206. doi: 10.1016/j.jshs.2015.08.001

9. Senkowski V, Gannon C. Branscum PJ. Behavior change techniques used in theory of planned behavior physical activity interventions among older adults: A systematic review. Journal of Aging \& Physical Activity. (2019) 1-9. doi: 10.1123/japa.2018-0103

10. Rich A, Brandes K, Mullan B. Hagger MS. Theory of planned behavior and adherence in chronic illness: a meta-analysis. Journal of Behavioral Medicine. (2015) 38:673-88. doi: 10.1007/s10865-015-9644-3

11. Prapavessis H, Gaston A. DeJesus S. The Theory of Planned Behavior as a model for understanding sedentary behavior. Psychology of Sport \& Exercise. (2015) 19:23-32. doi: 10.1016/j.psychsport.2015.02.001

12. Sniehotta FF, Presseau J, Araujo-Soares V. Time to retire the theory of planned behaviour. Health Psychol Rev. (2014) 8:1-7. doi: $10.1080 / 17437199.2013 .869710$

13. Ferreira G, Pereira MG. Physical activity: The importance of the extended theory of planned behavior, in type 2 diabetes patients. J Health Psychol. (2017) 22:1312-21. doi: 10.1177/1359105315626787

14. White KM, Terry DJ, Troup C, Rempel LA, Norman P, Mummery K, et al. An extended theory of planned behavior intervention for older adults with type 2 diabetes and cardiovascular disease. J Aging \& Physical Activity. (2012) 20:281-99. doi: 10.1123/japa.20.3.281

15. Umpierre D, Ribeiro PA, Kramer CK, Leitão CB, Zucatti AT, Azevedo MJ, et al. Physical activity advice only or structured exercise training and association with $\mathrm{HbA}_{1 c}$ levels in type 2 diabetes: a systematic review and meta-analysis. JAMA. (2011) 305:1790-9. doi: 10.1001/jama.2011.576

16. Davies CA. W Kerry M, Steele RM. The relationship between personality, theory of planned behaviour and physical activity in individuals with type II diabetes. British Journal of Sports Medicine. (2010) 44:97984. doi: $10.1136 /$ bjsm. 2008.050930

17. Ajzen I. The theory of planned behaviour: reactions and reflections. Psychol Health. (2011) 26:1113-27. doi: 10.1080/08870446.2011.613995

18. Godin G, Kok G. The theory of planned behavior: a review of its applications to health-related behaviors. Am J Health Promot. (1996) 11:8798. doi: 10.4278/0890-1171-11.2.87

19. Borland, R. Habits and temporality: A commentary on Hall and Fong's temporal self-regulation theory. Health Psychology Review. (2010) 4:6669. doi: 10.1080/17437191003700816

20. Sheeran P, Gollwitzer PM, Bargh JA. Nonconscious processes and health. Health Psychol. (2013) 32:460-473. doi: 10.1037/a0029203

21. Cheng OY, Yam CLY, Cheung NS, Lee PLP, Ngai MC, Lin CY. Extended theory of planned behavior on eating and physical activity. Am J Health Behav. (2019) 43:569-81. doi: 10.5993/AJHB.43.3.11

22. Lin CY, Oveisi S, Burri A, Pakpour AH. Theory of Planned Behavior including self-stigma and perceived barriers explain help-seeking behavior for sexual problems in Iranian women suffering from epilepsy. Epilepsy Behav. (2017) 68:123-8. doi: 10.1016/j.yebeh.2017.01.010
23. Zareban I, Karimy M, Araban M, Delaney D. Oral self-care behavior and its influencing factors in a sample of school children from Central Iran. Arch Public Health. (2021) 79:175. doi: 10.1186/s13690-021-00695-0

24. Lam TWL, Tsui YCJ, Fok L, Cheung LTO, Tsang EPK, Lee JC. The influences of emotional factors on householders' decarbonizing cooling behaviour in a subtropical Metropolitan City: An application of the extended theory of planned behaviour. Sci Total Environ. (2021) 807:150826. doi: 10.1016/j.scitotenv.2021.150826

25. Ajzen I. The theory of planned behavior. Organizational Behavior \& Human Decision Processes. (1991) 50:179-211. doi: 10.1016/0749-5978[91]90020-T

26. McEachan RRC, Conner M, Taylor NJ, Lawton RJ. Prospective prediction of health-related behaviours with the Theory of Planned Behaviour: a meta-analysis. Health Psychol Rev. (2011) 5:97-144. doi: 10.1080/17437199.2010.521684

27. Conner M, Armitage CJ. Extending the theory of planned behavior: A review and avenues for further research. J Appl Soc Psychol. (1998) 28:142964. doi: 10.1111/j.1559-1816.1998.tb01685.x

28. Jackson C, Smith A, Conner M. Applying an extended version of the theory of planned behaviour to physical activity. J Sports Sci. (2003) 21:11933. doi: $10.1080 / 0264041031000070976$

29. Terry DJ, Hogg MA, White KM. The theory of planned behavior: selfidentity, social identity and group norms. Br J Social Psychol. (1999) 38:22544. doi: 10.1348/014466699164149

30. de Bruijn G-J, van den Putte B. Exercise promotion: An integration of exercise self-identity, beliefs, intention, and behaviour. Eur J Sport Sci. (2012) 12:354-66. doi: 10.1080/17461391.2011.568631

31. Rise J, Sheeran P. Hukkelberg SJ. The role of self-identity in the theory of planned behavior: A meta-analysis. J Applied Social Psychol. (2010) 40:1085105. doi: 10.1111/j.1559-1816.2010.00611.x

32. Group NDR. A mass survey of diabetes mellitus in a population of 300,000 in 14 provinces and municipalities in China. Zhonghua Nei Ke Za Zhi. (1981) 20:678-83. doi: 10.1109/LPT.2006.877012

33. Rivis A, Sheeran P. Descriptive norms as an additional predictor in the theory of planned behaviour: A meta-analysis. Current Psychology. (2003) 22:218-33. doi: 10.1007/s12144-003-1018-2

34. Weinstein ND, Rothman AJ, Sutton SR. Stage theories of health behavior: conceptual and methodological issues. Health Psychology. (1998) 17:2909. doi: 10.1037/0278-6133.17.3.290

35. Lippke S, Nigg CR, Maddock JE. The theory of planned behavior within the stages of the transtheoretical model: latent structural modeling of stage-specific prediction patterns in physical activity. Structural Equation Modeling A Multidisciplinary Journal. (2007) 14:649-70. doi: 10.1080/10705510701575586

36. Courneya KS, Bobick TM. Integrating the theory of planned behavior with the processes and stages of change in the exercise domain. Psychol Sport Exerc. (2000) 1:41-56. doi: 10.1016/S1469-0292[00]00006-6

37. Gao M, Chen X, Sun X, Wang F, Fan L, Sun X. Predicting stage of exercise among patients with type 2 diabetes: a test of the extended theory of planned behavior. Patient Prefer Adherence. (2020) 14:277. doi: 10.2147/PPA.S236813

38. Kyriazos T A. Applied Psychometrics: Sample Size and Sample Power Considerations in Factor Analysis (EFA, CFA) and SEM in General. Psychology. (2018) 09:2207-30. doi: 10.4236/psych.2018.98126

39. Stewart DW, Gabriele JM, Fisher EB. Directive support, nondirective support, and health behaviors in a community sample. J Behav Med. (2012) 35:4929. doi: 10.1007/s10865-011-9377-x

40. Qu N, Li K. Study on the reliability and validity of international physical activity questionnaire (Chinese Vision, IPAQ). Zhonghua liu xing bing xue za zhi. (2004) 25:265-8. doi: 10.1016/j.csr.2003.12.006

41. Prochaska JO, Marcus BH. The transtheoretical model: applications to exercise. Med Sci Sports Exerc. (1994) 26:1400-4. doi: 10.1249/00005768-199411000-00016

42. Plotnikoff RC, Lippke S, Courneya K, Birkett N, Sigal R. Physical activity and diabetes: An application of the theory of planned behaviour to explain physical activity for Type 1 and Type 2 diabetes in an adult population sample. Psychology and Health. (2010) 25:7-23. doi: 10.1080/08870440802160984

43. Boudreau F, Godin G. Understanding physical activity intentions among French Canadians with type 2 diabetes: an extension of Ajzen's theory of 
planned behaviour. International Journal of Behavioral Nutrition and Physical Activity. (2009) 6:35. doi: 10.1186/1479-5868-6-35

44. Plotnikoff RC, Lubans DR, Trinh L, Craig CL, A. 15-year longitudinal test of the theory of planned behaviour to predict physical activity in a randomized national sample of Canadian adults. Psychol Sport Exerc. (2012) 13:5217. doi: $10.1016 /$ j.psychsport.2012.02.005

45. Plotnikoff RC, Lubans DR, Costigan SA, McCargar L, A. test of the theory of planned behavior to predict physical activity in an overweight/obese population sample of adolescents from Alberta, Canada. Health Education \& Behavior. (2013) 40:415-25. doi: 10.1177/1090198112455642

46. Courneya KS, Plotnikoff RC, Hotz SB, Birkett NJ. Predicting exercise stage transitions over two consecutive 6-month periods: A test of the theory of planned behaviour in a population-based sample. Br J Health Psychol. (2001) 6:135-50. doi: 10.1348/135910701169115

47. Norman P, Conner M, Bell R. The theory of planned behaviour and exercise: Evidence for the moderating role of past behaviour. Br J Health Psychol. (2000) 5:249-61. doi: 10.1348/135910700168892

48. Hamilton K, White KM. Extending the theory of planned behavior: the role of self and social influences in predicting adolescent regular moderate-tovigorous physical activity. Journal of Sport and Exercise Psychology. (2008) 30:56-74. doi: 10.1123/jsep.30.1.56

49. Hagger MS, Chatzisarantis N, Biddle SJ. The influence of self-efficacy and past behaviour on the physical activity intentions of young people. J Sports Sci. (2001) 19:711-25. doi: 10.1080/02640410152475847

50. de Bruijn G-J, Verkooijen K, de Vries NK, van den Putte B. Antecedents of self identity and consequences for action control: An application of the theory of planned behaviour in the exercise domain. Psychol Sport Exerc. (2012) 13:771-8. doi: 10.1016/j.psychsport.2012.05.008

51. Rook KS, Ituarte PH. Social control, social support, and companionship in older adults' family relationships and friendships. Pers Relatsh. (1999) 6:199-211. doi: 10.1111/j.1475-6811.1999.tb00187.x
52. Godin G, Valois P, Shephard RJ, Desharnais R. Prediction of leisure-time exercise behavior: a path analysis (LISREL V) model. J Behav Med. (1987) 10:145-58. doi: 10.1007/BF00846423

53. Kimiecik J. Predicting vigorous physical activity of corporate employees: Comparing the theories of reasoned action and planned behavior. J Sport and Exercise Psychol. (1992) 14:192-206. doi: 10.1123/jsep.14.2.192

54. Courneya KS. Understanding readiness for regular physical activity in older individuals: An application of the theory of planned behavior. Health Psychol. (1995) 14:80. doi: 10.1037/0278-6133.14.1.80

55. Conner M, Godin G, Sheeran P, et al. Some feelings are more important: cognitive attitudes, affective attitudes, anticipated affect, and blood donation. Health Psychol. (2012) 32:264-72. doi: 10.1037/a0028500

Conflict of Interest: The authors declare that the research was conducted in the absence of any commercial or financial relationships that could be construed as a potential conflict of interest.

Publisher's Note: All claims expressed in this article are solely those of the authors and do not necessarily represent those of their affiliated organizations, or those of the publisher, the editors and the reviewers. Any product that may be evaluated in this article, or claim that may be made by its manufacturer, is not guaranteed or endorsed by the publisher.

Copyright $\odot 2021$ Gao, Chen, Sun, Feng and Fisher. This is an open-access article distributed under the terms of the Creative Commons Attribution License (CC BY). The use, distribution or reproduction in other forums is permitted, provided the original author(s) and the copyright owner(s) are credited and that the original publication in this journal is cited, in accordance with accepted academic practice. No use, distribution or reproduction is permitted which does not comply with these terms. 